\title{
Capsulolabral Adhesions After Hip Arthroscopy for the Treatment of Femoroacetabular Impingement: Strategies During Rehabilitation and Return to Sport to Reduce the Risk of Revision
}

\author{
Marc J. Philippon, M.D., Mark Ryan, M.S., A.T.C., C.S.C.S., Maitland B. Martin, B.S., and \\ Johnny Huard, Ph.D.
}

\begin{abstract}
This article will review various strategies such as passive range of motion modalities, active range of motion movements, and pharmacological interventions for the prevention of adhesion formation after hip arthroscopy. Capsulolabral adhesions are a common cause of revision hip arthroscopy for which treatment methods are still evolving. Efforts to prevent and limit their formation postoperatively, including adjuncts such as losartan, as well as the use of consistent passive and active, multiplanar movements, both therapist and continuous passive motion machine assisted, should be considered.
\end{abstract}

$\mathbf{H}$ ip arthroscopy is a common orthopaedic surgery performed primarily on a younger, athletic population. Evaluating outcomes for the surgery, studies show a range of satisfaction of between $80 \%$ to $95 \%$ and return to sport from $60 \%$ to $95 \% .^{1-3}$ As with all surgeries, there can be complications, and this article will outline clinical strategies for postoperative care to reduce the risk of one of the more common complications leading to revision hip arthroscopy and a lysis of

From the Steadman Philippon Research Institute (M.J.P., M.B.M., J.H.), Vail, Colorado; and the Steadman Clinic and United States Coalition for the Prevention of Illness and Injury in Sport (M.R.), Vail, Colorado, U.S.A.

The authors report the following potential conflicts of interest or sources of funding: M.J.P. reports grants from Smith and Nephew, Ossur, and Siemens; personal fees from Smith and Nephew and Siemens; other from Arthrosurface, MJP Innovations, LLC, MIS, Bledsoe, ConMed Linvatec, DonJoy, Slack, Elsevier, VaIL Valley Surgery Center, EffRX, Vail MSO Holdings LLC, and Synthes GMBH. J.H. reports other from Cook Myocytes Inc. Full ICMJE author disclosure forms are available for this article online, as supplementary material.

Received September 17, 2021; accepted October 30, 2021

Address correspondence to Marc J. Philippon, M.D., Steadman Philippon Research Institute, The Steadman Clinic, 181 W Meadow Dr, Ste 400, Vail, CO 81657, U.S.A.E-mail: drphilippon@sprivail.org

(C) 2021 THE AUTHORS. Published by Elsevier Inc. on behalf of the Arthroscopy Association of North America. This is an open access article under the CC BY-NC-ND license (http://creativecommons.org/licenses/by-nc-nd/4.0/).

2666-061X/211384

https://doi.org/10.1016/j.asmr.2021.10.031 adhesions, capsulolabral adhesions. With the establishment of adhesions as a risk factor for failure after arthroscopic hip surgery for femoroacetabular impingement and evidence of risk factors for the formation of the adhesions, preventative measures are of key importance. ${ }^{4}$ This article will review various strategies such as passive range of motion (PROM) modalities, active range of motion (AROM) movements, and pharmacological interventions for the prevention of postoperative adhesion formation.

As part of a normal healing response, proliferation occurs wherein the human body deposits extracellular matrix and collagen to repair damaged tissue. This same healing mechanism occurs after surgical procedures. Although extracellular matrix/collagen deposition for tissue repair is not normally an issue, in excess, it can lead to fibrosis, or scar tissue/adhesion formation. This becomes problematic when the adhesions attach tissues together that would not normally be connected. In the setting of hip arthroscopy, adhesions form most frequently between the iliopsoas tendon and the capsule or between the capsule and the labrum and are recognized as a potential cause of continued pain and reduced range of motion (ROM) after operation. ${ }^{4,5}$ In particular, severe capsulolabral adhesions (those between the labrum and the capsule) compromise the function of the labrum by tethering the capsule, thereby pulling the labrum away from the femoral 
head. This may lead to loss of the hip fluid seal or eversion of the labrum. ${ }^{4-6}$

Patients may describe feelings of "giving way" or catching, or they may be apprehensive to attempt ranges of motion or describe persistent pain. Patients with adhesions have reported pinching/pain with flexion and/ or pulling with external rotation and extension movements. Signs may include synovitis and a possible loss of suction seal and may be thoroughly assessed through diagnostic arthroscopy. ${ }^{\text {? }}$

The pathophysiology for the formation of postoperative capsulolabral adhesions is not yet understood. The high vascularity present in and around the capsule, the labrum and the capsulolabral recess has been previously investigated as a potential cause for capsulolabral adhesions. Additionally, the presence of suture materials from prior surgeries have been hypothesized to initiate a biological response resulting in adhesion formation. In the senior author's experience, patients who develop adhesions follow a fairly positive postoperative recovery path initially, then may describe an increase in discomfort with the movements described above. This can occur any time after surgery but is often seen at approximately 10 to 16 weeks after operation because of the natural maturation of scar tissue. Particular collagen formation (keloid/hypertrophic) tendencies should be considered when assessing for adhesion formation, along with the potential postoperative re-bleeds after surgery because of a fall or accident, rehabilitation interventions, or patient risk factors discussed in the following paragraph.

Willimon et al. ${ }^{8}$ examined risk factors for capsulolabral adhesions in 1264 primary hip arthroscopy procedures between 2005 to 2009 and found that patients under 30 years of age were 5.9 times more likely to develop adhesions. Moreover, patients who did not perform hip circumduction after operation were 4.1 times more likely to have adhesions than those who did hip circumduction, and patients who had Modified Harris Hip Scores below 50 were 2.4 times more likely. Patients having a microfracture procedure as part of the hip arthroscopy procedure were 3.1 times less likely to develop adhesions. In this study, revision surgeries were performed on $4.7 \%$ of the patients as a result of adhesion formation. ${ }^{8}$

This article will review various strategies such as PROM modalities, AROM movements, and pharmacological interventions for the prevention of adhesion formation after hip arthroscopy. Capsulolabral adhesions are a common cause of revision hip arthroscopy for which treatment methods are still evolving. Efforts to prevent and limit their formation after surgery, including adjuncts such as losartan, as well as the use of consistent passive and active, multiplanar movements, both therapist and continuous passive motion machine assisted, should be considered.

\section{Postoperative Strategies}

Although there is not a standardized rehabilitation protocol for hip arthroscopy, many protocols have been published. Several postoperative strategies for reducing the risk of adhesions are described in the literature. ${ }^{9,10}$ Several of these will be discussed in the following paragraphs.

\section{PROM Strategies}

\section{Hip Circumduction}

As noted above, hip circumduction is a vital strategy for decreasing the risk of adhesions. It is a form of PROM performed by a clinician or caregiver to the patient. The patient lies supine, close to the edge of the treatment table or bed (Fig 1). The "circumductor" places the surgical leg at approximately $60^{\circ}$ to $70^{\circ}$ of hip and knee flexion either on top of the shoulder or cradle supported by the arms. The leg is then smoothly rotated in a small circle approximately 8 to 10 inches $(20-25 \mathrm{~cm})$ in diameter. The circumduction protocol currently used is 3 to 4 times per day, 30 repetitions clockwise and 30 repetitions counterclockwise. We recommend circumduction be performed in this manner for 10 weeks after operation. Other PROM movements can also be implemented during the rehabilitation process, including internal rotation (IR) at 90/90 (Fig 2), abduction/adduction (Fig 3), and flexion/extension (Fig 4).

\section{Continuous Passive Motion Machine (CPM)}

The CPM is another tool to keep the surgical hip moving in a flexion/extension movement pattern and is used when the patient is sleeping or resting (Fig 5). Potential benefits include improving the alignment of collagen during the healing process, as well as decreasing the risk of adhesions because of the constant motion. The range of motion is progressed weekly as patient tolerates. A common protocol for use as follows:

- Use 4 to 8 hours a day. Non-microfracture patients for 4 weeks. Microfracture patients use for up to 8 weeks (dependent on length of limited weightbearing duration).

- ROM settings: first week $10^{\circ}$ to $45^{\circ}$, second week $0^{\circ}$ to $60^{\circ}$, third week $0^{\circ}$ to $70^{\circ}$, fourth week and beyond $0^{\circ}$ to $80^{\circ}$

The following are tips in the use of the CPM:

- Orient at $10^{\circ}$ out from midline of the body

- Prop pillow/towel under nonsurgical buttock to even out pelvis

- Place small, folded towel above outside of the knee to control external rotation

- Have help getting into and out of CPM to reduce hip flexor activation as needed

- Limit to 8 hours of consecutive use 

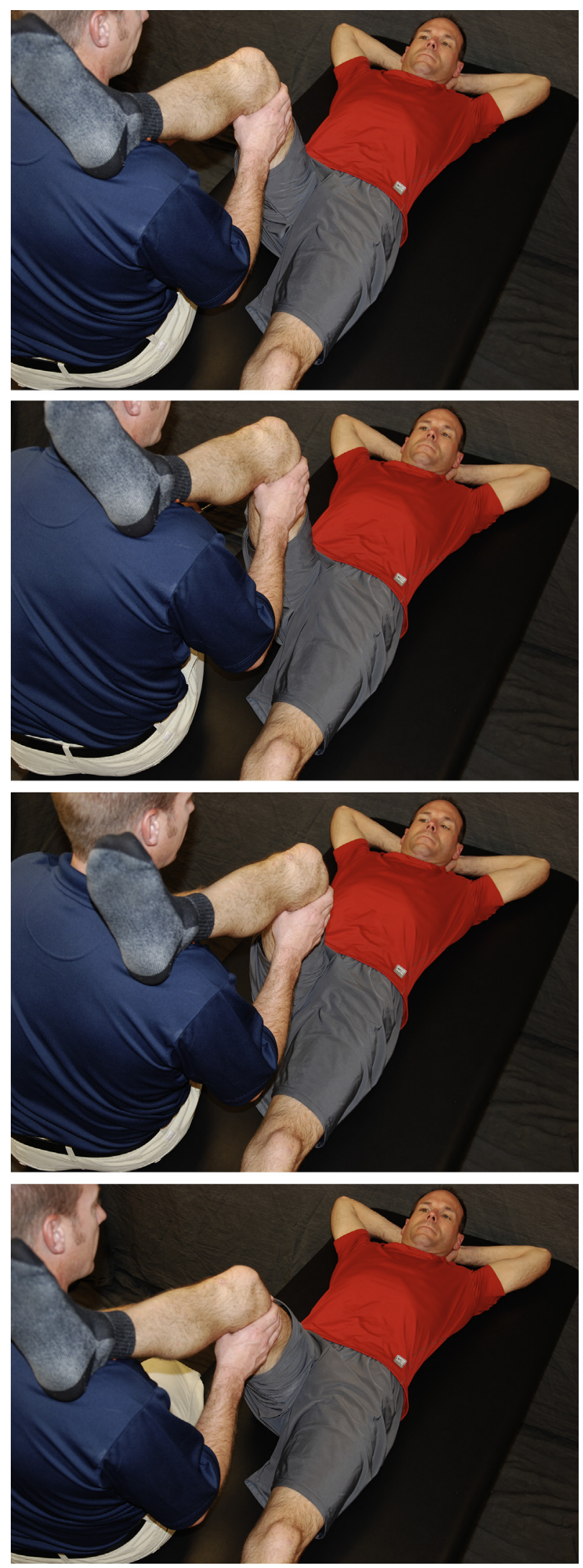

Fig 1. Circumduction: The caregiver rests the surgical leg on their shoulder and grasps the thigh of the patient. Using hands and body rotation, the patient's hip is rotated in a clockwise direction in a small circle (8-10 inches). Repeat 10 times, then move in a counterclockwise direction for 10 repetitions.
- Recommend placing in the middle of bed to reduce risk of the CPM falling off the bed

Additional research into the therapeutic boundaries of continuous passive motion machines has shown that this form of therapy is effective in staving off the pathologic stages of joint stiffness. Often used as an adjunct after total knee arthroplasty, CPM machines not only reduce joint stiffness but also aid in the process of maintaining articular cartilage. Hyaline cartilage requires movement for the cycling of synovial fluid and diffusion of nutrients as it is largely avascular. Continuous passive motion machines therefore may aid in the maintenance and nutrition of articular cartilage.

\section{AROM}

AROM has been shown to decrease the incidence of adhesions $^{11}$ and is implemented throughout the rehabilitation process. Early muscle activation is instrumental in the function of the lymphatic system through the lymphatic pump. ${ }^{12}$ Several modalities are available to patients.

\section{Stationary Cycling}

Patients typically tolerate non-resisted stationary cycling as early as day 1 after operation (Fig 6). This is a
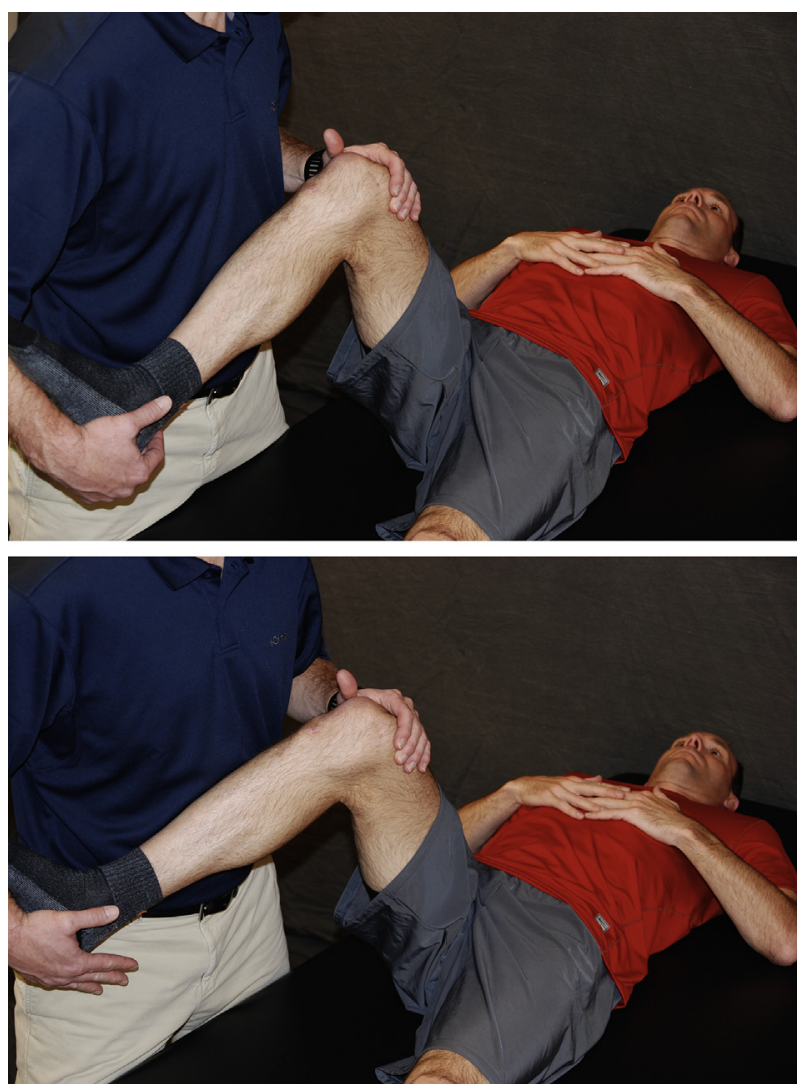

Fig 2. With the patient lying supine, hold surgical leg at approximately $90^{\circ} / 90^{\circ}$ of hip and knee flexion. Slowly rotate foot inward and outward into hip external rotation and internal rotation as tolerated by patient. 

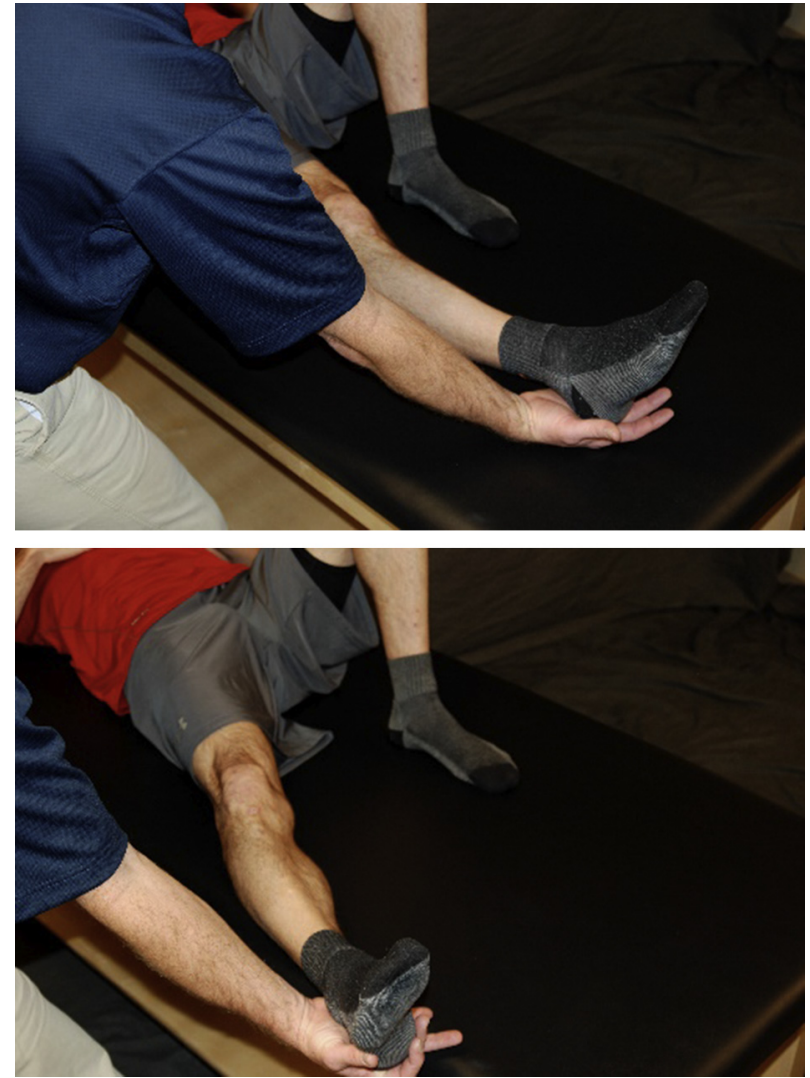

Fig 3. With the patient lying supine, the caregiver holds the heel of the surgical leg in the palm of the hand and passively abducts the leg to approximately $45^{\circ}$. Return to neutral position, repeat 20 times.

non-weightbearing activity and therefore an excellent choice to actively move the hip joint in the sagittal plane. Patients can pedal both forward and backward as tolerated.

\section{Aquatic Therapy}

Another movement modality for AROM is water therapy accessing the benefits of the limited gravitational force setting. It allows patients to perform functional activities in a hip-friendly environment to maintain neuromuscular patterns such as running, walking, and squatting. Additionally, it gives patients the opportunity to move on their own and take a more active role in their recovery. The increased hydrostatic pressure created by submerging a patient in the water increases the efficiency of the heart and helps in venous return. It also applies compression to joints, muscles, and other soft tissues, facilitating reduction of swelling and aiding lymphatic drainage. ${ }^{13,14,15}$ Aquatic therapy may begin as early as 3 to 4 days after operation, with the use of waterproof dressings.

\section{Deep Water Aquajogging}

Deep water aquajogging is performed in water deep enough to prevent the feet from touching the bottom of
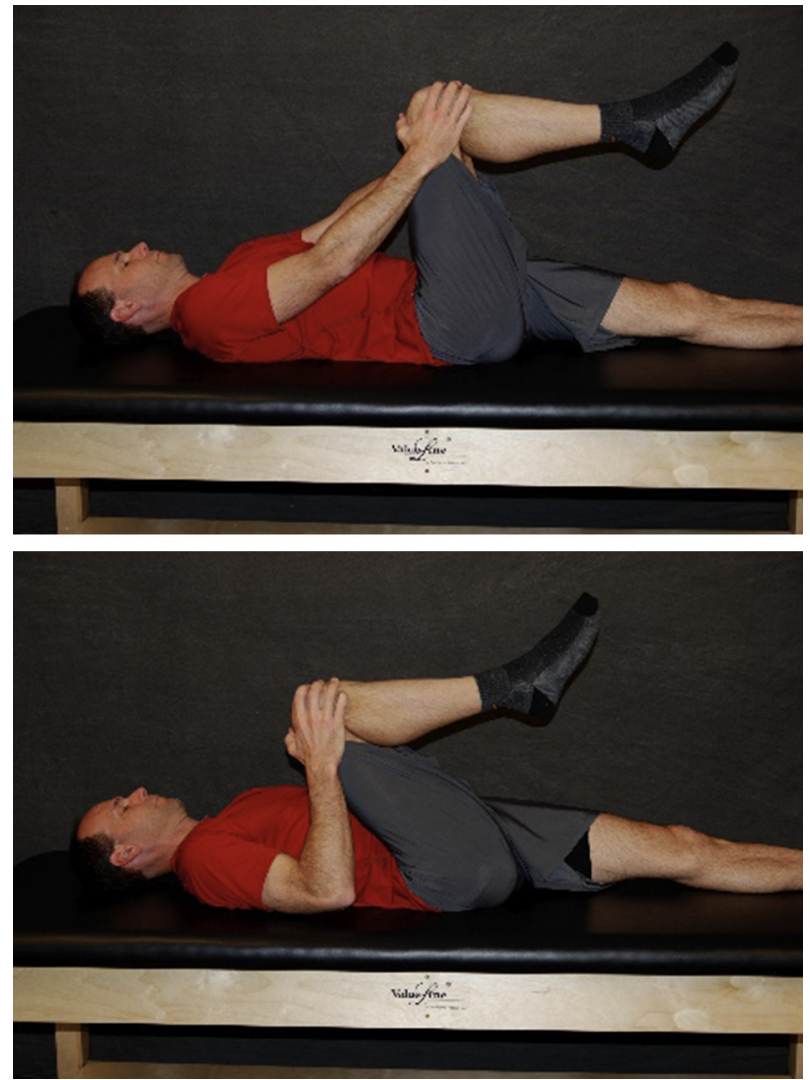

Fig 4. With the patient lying supine, the patient or caregiver passively moves the surgical leg into flexion as tolerated.

the pool. A flotation belt or device should be worn by the patient to allow the patient to safely stay above the surface of the water and focus on aquajogging with their best form. The running movement should respect any range of motion restrictions set by the surgeon, typically limited extension beyond $0^{\circ}$ for the first 2.5 weeks to protect the anterior capsular closure. After that time period, the patient can progressively increase the extension ROM beyond $0^{\circ}$.

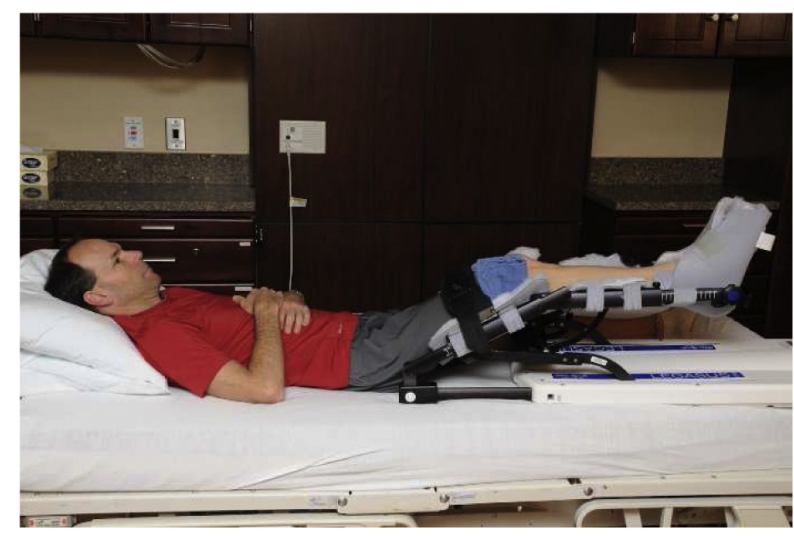

Fig 5. A continuous passive motion machine. 


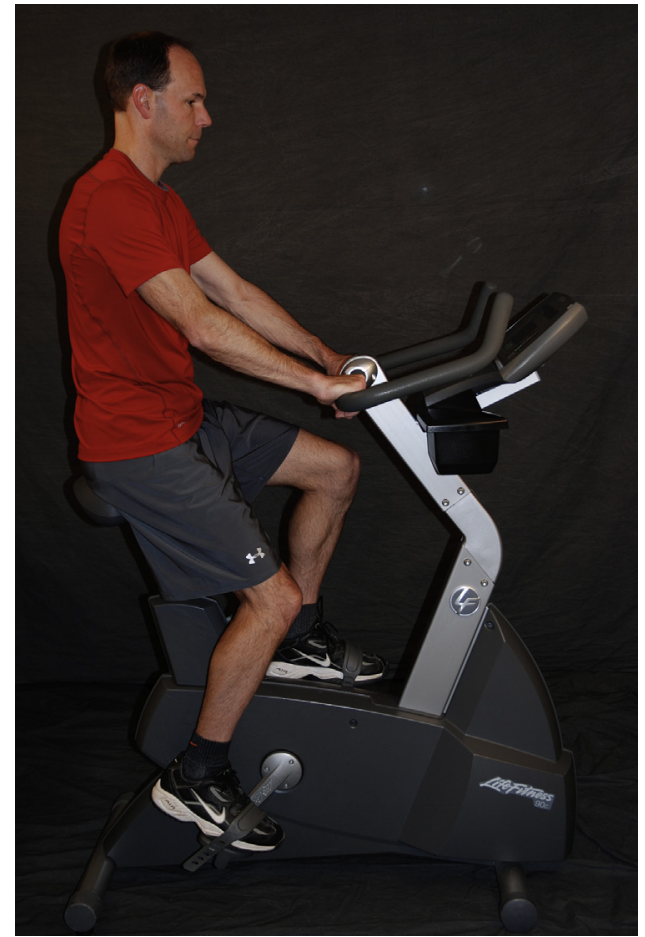

Fig 6. Stationary cycling. Initially performed with no resistance, progressing to resisted cycling at 7 weeks after surgery.

\section{Supine Flutter Kicks}

This exercise is also performed while wearing the flotation device. The patient lies supine in the water and performs light flutter kicks with a focus on gluteal activation to draw the legs below the surface of the water.

\section{Water Walking}

Early water walking is an AROM exercise that maintains the neuromuscular pathways for gait. Done in chest-deep water immediately after surgery, it can be progressed to waist-deep water as weightbearing tolerance increases. Forward, backward, and lateral walking are all encouraged to work on flexion/ Extension and Abduction/ Adduction movements.

\section{Mini-squats With a Calf Raise}

Mini-squats with a calf raise may be performed to a tolerable depth to work on "triple extension" (ankleknee-hip extension).

\section{Standing Abduction}

Standing abduction is used to maintain glute medius function and actively stretch the hip adductors.

\section{Additional AROM Physical Therapy Exercise Examples}

See Figures 7 to 12 for the following examples of AROM physical therapy: cat/camel (Fig 7), quadruped rocking (Fig 8), supine abduction/adduction (Fig 9), standing abduction (Fig 10), heel slides (Fig 11), and stool rotations (Fig 12).

\section{Biologics}

\section{Losartan}

In addition to the physical interventions than can be used to reduce the risk of adhesions, an additional adjunct for consideration is the angiotensin II-type receptor blocker, Losartan. ${ }^{16}$ Acting within the renin-angiotensin blood pressure-regulating system, the end product of angiotensin II modulates transforming growth factor $-\beta 1$ (TGF- $\beta 1$ ), a key cytokine active in the formation of fibrosis in skeletal muscle tissue. ${ }^{17}$ It is hypothesized that blocking the activation of TGF- $\beta 1$ would limit the formation of fibrosis and improve muscle regeneration. ${ }^{17}$ Although widely used to treat hypertension and congestive heart failure, losartan is the first orally active, non-peptide angiotensin II-type receptor blocker that is commercially available. ${ }^{18}$ Studies have supported the efficacy of losartan reducing fibrosis in lung, liver, and kidney tissues. ${ }^{19-24}$ Furthermore, in a study examining
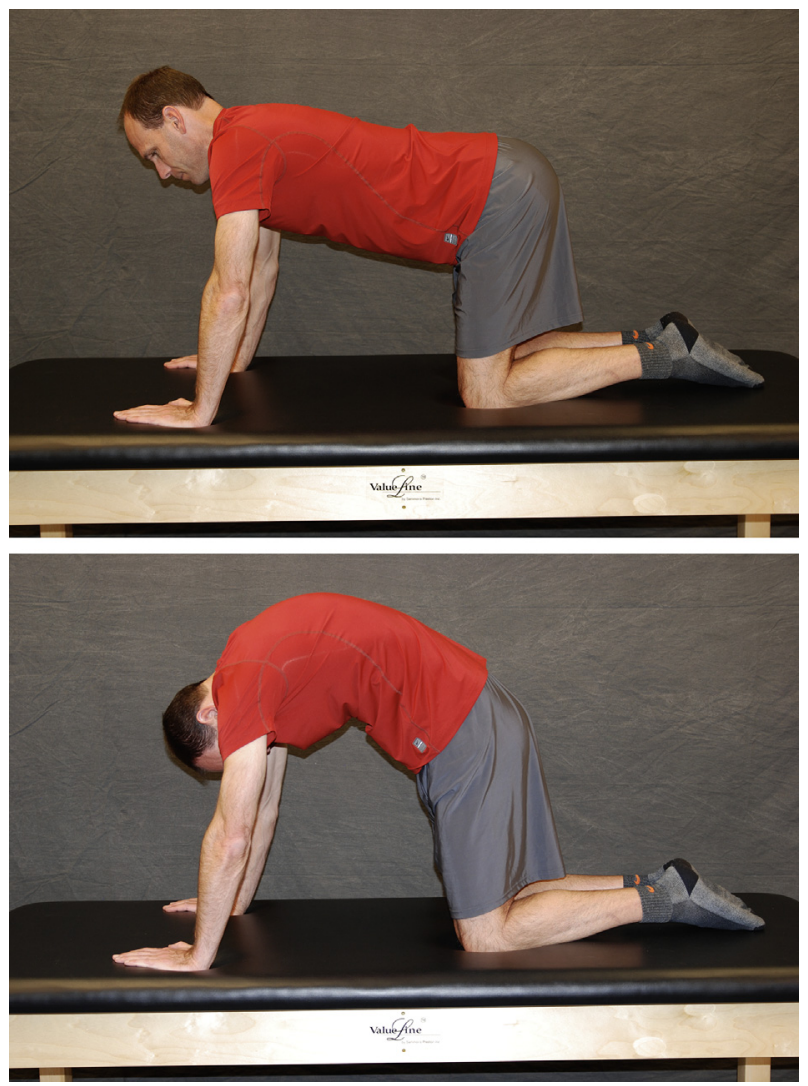

Fig 7. Quadruped, the patient actively flexes the spine with a subsequent anterior pelvic tilt. The patient then moves to spinal extension and posterior pelvic tilt. 

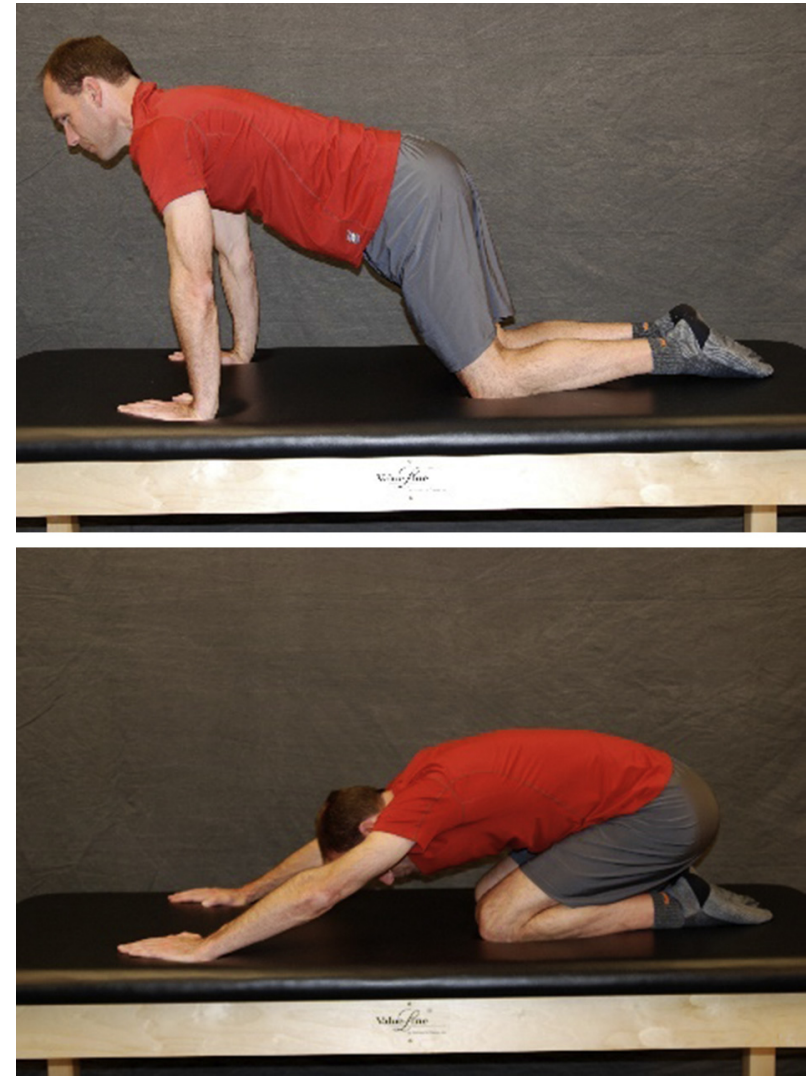

Fig 8. The patient is quadruped and gently rocks forward extending hips to neutral, then pushes back into tolerated hip flexion.

endurance athletes using an angiotensin blockade, it was found that the athletes had improved skeletal muscle regeneration after injury, supporting the use of losartan for non-hypertension or cardiac pathologies. $^{25}$

Studies have further investigated the effect of losartan on tissue other than skeletal muscle and in conjunction to other treatment therapies. In a study by Terada et al., patients treated with platelet-rich plasma + losartan combinatorial therapy showed enhanced angiogenesis and follistatin expression when compared to those treated with platelet-rich plasma only, supporting the efficacy of losartan in improving overall muscle healing. ${ }^{18}$ When used in addition to muscle derived stem cells in a mouse model, the use of losartan resulted in significantly reduced scar tissue formation, increased number of regenerating myofibrils and overall improved functional muscle recovery. ${ }^{26}$ Additionally, Utsunomiya et al. ${ }^{27}$ and Logan et al. ${ }^{28}$ found that when biologically regulated bone marrow stimulation was performed in conjunction to oral losartan intake, the cartilage repair was superior to the control population, resulting in increased hyaline cartilage formation and reduced fibrocartilage formation.
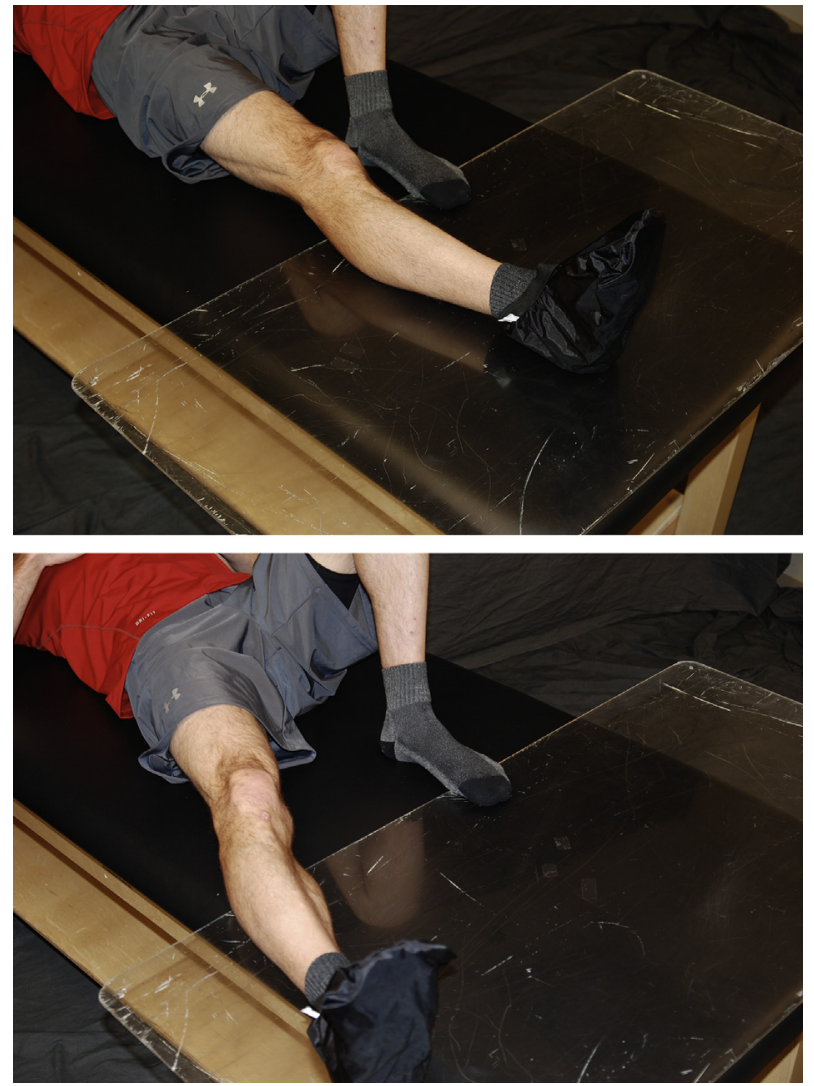

Fig 9. With the patient lying supine, with a slide board and sock, the patient actively abducts the surgical hip using the gluteus medius and then returns to neutral using hip adductors.

Although losartan efficacy has been researched across multiple tissue types, there is limited evidence for the efficacy of losartan in the reduction of postoperative adhesions after hip arthroscopy. Regarding its use in the

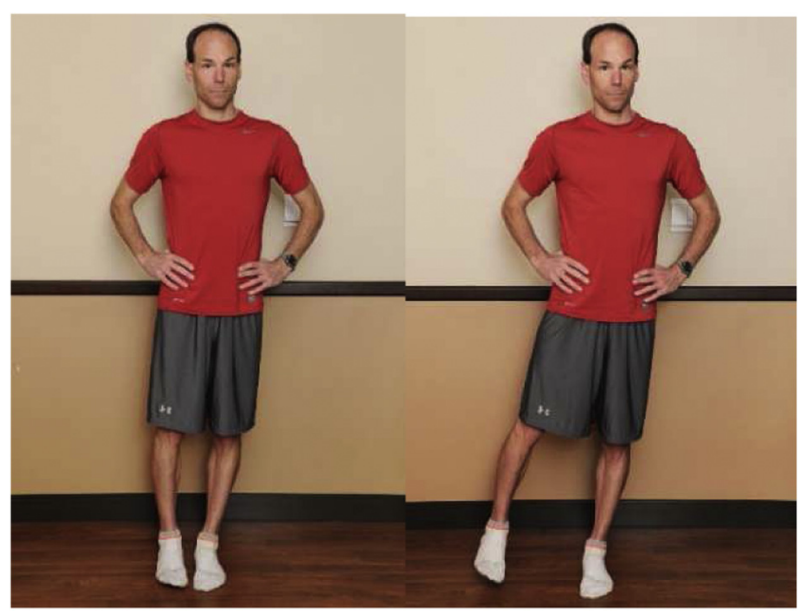

Fig 10. With the patient standing on the nonsurgical leg, they maintain a level pelvis, slightly internally rotate the hip, and actively move into hip abduction with the gluteus medius. Return to starting position. 

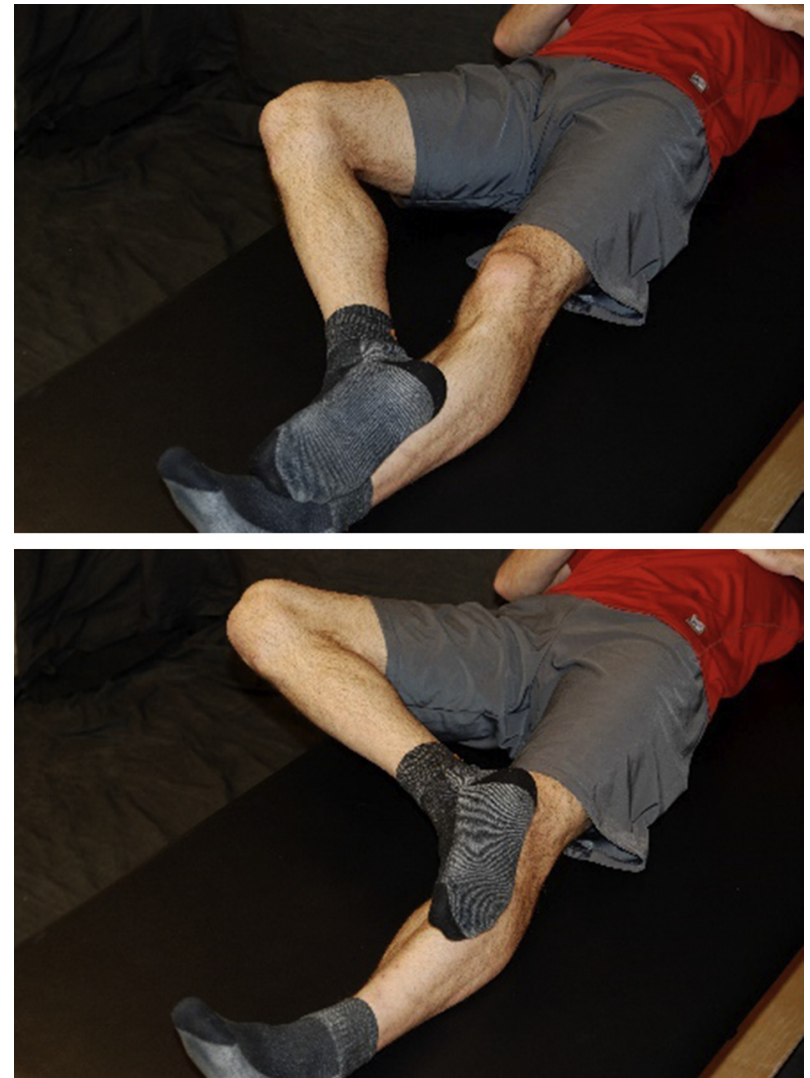

Fig 11. Lying supine, patient gently glides the heel of the surgical leg up the nonsurgical leg as tolerated.

murine model of biologically regulated bone marrow stimulation, losartan may be used as an adjunct to microfracture, which has been shown to decrease risk of forming adhesions after surgery. Additionally, because of its mechanism of modulating TGF- $\beta 1$ and subsequent fibrosis, it has been hypothesized that losartan may play a key role in limiting the formation of adhesions directly, although there is no current evidence to support its efficacy in either case.

The current protocol for the use of losartan is $12.5 \mathrm{mg}$ twice a day for 6 weeks after surgery. Further study is required to examine the efficacy of losartan, including the dose, frequency, and duration, which is used as an
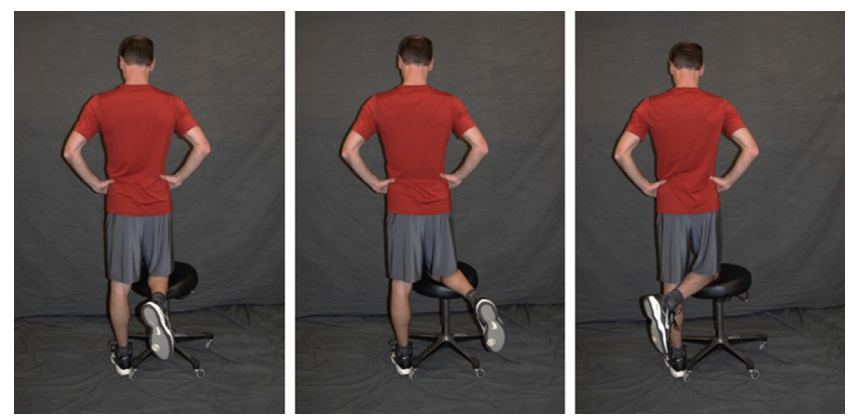

Fig 12. The patient rests the surgical knee on a rotating stool and gently moves the hip into internal and external rotation. effective treatment to reduce the formation of adhesions.

In conclusion, comprehensive efforts to prevent and limit the formation of adhesions, including postoperative adjuncts such as losartan, as well as the use of consistent active and passive multiplanar movement patterns, should be considered to limit subsequent negative surgical outcomes. Future studies of the individual strategies, as well as the collective group of interventions, will provide greater insight into their efficacy.

\section{References}

1. Minkara A, Westermann R, Rosneck J, Lynch TS. Systematic review and meta-analysis of outcomes after hip arthroscopy in femoroacetabular impingement. Am J Sports Med 2019;47:488-500.

2. Litrenta J, Mu B, Ortiz-Declet V, Chen A, Perets I, Wojnowski N, Domb B. Hip arthroscopy successfully treats femoroacetabular impingement in adolescent athletes. J. Pediatr Orthop 2019;40(3):e156-el60.

3. O'Connor M, Minkara A, Westermann R, Rosneck J, Lynch. Return to play after hip arthroscopy: A systematic review and meta-analysis. Am J Sports Med 2018;46: 2780-2788.

4. Philippon MJ, Schenker ML, Briggs KK, Kuppersmith DA, Maxwell RB, Stubbs AJ. Revision hip arthroscopy. Am J Sports Med 2007;35:1918-1921.

5. Sardana V, Philippon MJ, de Sa D, et al. Revision hip arthroscopy indications and outcomes: A systematic review. Arthroscopy 2015;31:2047-2055.

6. Beck M. Groin pain after open FAI surgery: The role of intraarticular adhesions. Clin Orthop 2009;467:769-774.

7. Philippon M, Ferro F, Nepple J. Hip capsulolabral spacer placement for the treatment of severe capsulolabral adhesions after hip arthroscopy. Arthroscopy Tech 2014;3: 289-292.

8. Willimon SC, Briggs K, Philippon M. Intraarticular adhesions following hip arthroscopy: A risk factor analysis. Knee Surg Sports Traumatol Arthrosc 2014;22:822-825.

9. Wahoff M, Ryan M. Rehabilitation after hip femoroacetabular impingement arthroscopy. Clin Sports Med $2011 ; 30: 463-482$.

10. Malloy P, Gray K, Wolff AB. Rehabilitation after hip arthroscopy: A movement control-based perspective. Clin Sports Med 2016;35:503-521.

11. Dehne E, Torp RP. Treatment of joint injuries by immediate mobilization. Based upon the spinal adaptation concept. Clin Orthop Rel Res 1971;77:218-232.

12. Tzani I, Tsichlaki M, Zerva E, Papathanasiou G, Dimakakos E. Physiotherapeutic rehabilitation of lymphedema: State of the art. Lymphology 2008;51:1-12.

13. Gautu AP, Maiya AG, Vidyasagar MS. Effects of homebased exercise program on lymphedema and quality of life in female post-mastectomy patients_ Pre-post intervention study. J Rehabil Res Dev 2011;48:1261-1268.

14. Johansson K, Tibe K, Weibull A, et al. Low intensity resistance exercise for breast cancer patients with arm lymphedema with or without compression sleeve. Lymphology 2005:38:167-180. 
15. Mosley AL, Piller AB, Carati CJ. The effect of gentle arm exercise and deep breathing on secondary arm lymphedema. Lymphology 2005;38:135-136.

16. Huard J, Bolia I, Briggs K, Utsunomiya H, Lowe WR, Philippon MJ. Potential usefulness of losartan as an antifibrotic agent and adjunct to platelet-rich plasma therapy to improve muscle healing and cartilage repair and prevent adhesion formation. Orthopedics 2018;41(5): e591-e597.

17. Bedair HS, Karthikeyan T, Quintero A, Li Y, Huard J. Angiotensin II receptor blockade administered after injury improves muscle regeneration and decreases fibrosis in normal skeletal muscle. Am J Sports Med 2008;36:1548-1554.

18. Terada S, Ota S, Kobayashi M, et al. Use of an antifibrotic agent improves the effect of platelet-rich plasma on muscle healing after injury. J Bone Joint Surg Am 2013;95: 980-988.

19. el-Agroudy AE, Hassan NA, Foda MA, et al. Effect of angiotensin II receptor blocker on plasma levels of TGFbeta 1 and interstitial fibrosis in hypertensive kidney transplant patients. Am J Nephrol 2003;23:300-306.

20. Amthor H, Nicholas G, McKinnell I, et al. Follistatin complexes Myostatin and antagonises Myostatin-mediated inhibition of myogenesis. Dev Biol 2004;270:19-30.

21. Lim DS, Lutucuta S, Bachireddy P, et al. Angiotensin II blockade reverses myocardial fibrosis in a transgenic mouse model of human hypertrophic cardiomyopathy. Circulation 2001;103:789-791.
22. Uhal BD, Wang R, Laukka J, Zhuang J, SoledadConrad V, Filippatos G. Inhibition of amiodarone-induced lung fibrosis but not alveolitis by angiotensin system antagonists. Pharmacol Toxicol 2003;92:81-87.

23. Otsuka M, Takahashi H, Shiratori M, Chiba H, Abe S. Reduction of bleomycin-induced lung fibrosis by candesartan Cilexetil, an angiotensin II type 1 receptor antagonist. Thorax 2004;59:31-38.

24. Paizis G, Gilbert RE, Cooper ME, et al. Effect of angiotensin II type 1 receptor blockade on experimental hepatic fibrogenesis. J Hepatol 2001;35:376-385.

25. Onder G, Vedova CD, Pahor M. Effects of ACE inhibitors on skeletal muscle. Curr Pharm Des 2006;12:2057-2064.

26. Kobayashi M, Ota S, Terada S, Kawakami Y, Otsuka T, Fu FH, et al. The combined use of losartan and musclederived stem cells significantly improves the functional recovery of muscle in a young mouse model of contusion injuries. Am J Sports Med 2016;44:3252-3261.

27. Utsunomiya H, Gao X, Deng Z, Cheng H, Nakama G, Scibetta AC, et al. Biologically regulated marrow stimulation by blocking TGF- $\beta 1$ with losartan oral administration results in hyaline-like cartilage repair: A rabbit osteochondral defect model. Am J Sports Med 2020;48:974-984.

28. Logan CA, Gao X, Utsunomiya H, Scibetta AC, Talwar M, Ravuri SK, et al. The beneficial effect of an intra-articular injection of losartan on microfracture-mediated cartilage repair is dose dependent. Am J Sports Med 2021;49: 2509-2521. 